\title{
Erratum to: The effect of vitamin D supplements on the severity of restless legs syndrome
}

\author{
Siraj Wali ${ }^{1,3} \cdot$ Afnan Shukr $^{1} \cdot$ Ayah Boudal $^{1} \cdot$ Ahmed Alsaiari $^{1} \cdot$ Ayman Krayem $^{2}$
}

Published online: 2 October 2015

(C) Springer-Verlag Berlin Heidelberg 2015

Erratum to: Int Urogynecol J 2015 May;19(2):579-83

DOI: 10.1007/s11325-014-1049-y

The authors regret that the name of the fourth author Ahmed Alsaiari was incorrectly submitted as Ahmad Alsaiari.

The correct name is presented above.

The online version of the original article can be found at http:dx.doi.org/ 10.1007/s11325-014-1049-y.

Siraj Wali

Sowali@kau.edu.sa

1 Sleep Medicine and Research Center, King Abdulaziz University, Jeddah, Saudi Arabia

2 Sleep Disorders Center, King Abdulaziz Medical City, Jeddah, Saudi Arabia

3 Associate Professor of Medicine College of Medicine, King Abdulaziz University Sleep Medicine and Research Center King Abdulaziz University Hospital, P.O. Box 80215, Jeddah 21589, Saudi Arabia 